\title{
Curative effect of artificial femoral head replacement and its effect on hip joint function and complications of senile patients with femoral intertrochanteric fracture
}

\author{
HAIWEI SHI, LONG XIAO and ZHIFANG WANG \\ Department of Orthopedics and Traumatology, Zhangjiagang TCM Hospital Affiliated to Nanjing \\ University of Chinese Medicine, Zhangjiagang, Jiangsu 215600, P.R. China
}

Received October 21, 2017; Accepted May 9, 2018

DOI: $10.3892 / \mathrm{etm} .2018 .6214$

\begin{abstract}
Curative effect of artificial femoral head replacement on hip joint function and complications of elderly patients with femoral intertrochanteric fracture were investigated. Eighty patients who were operated for femoral intertrochanteric fractures operation were randomly divided into observation group $(n=40)$ and control group $(n=40)$. The observation group was treated with artificial femoral head replacement, while the control group received internal proximal femur locking plate fixation. In the observation group, the operation time was shorter than that in the control group $(\mathrm{P}<0.05)$. The intraoperative bleeding was less than that in the control group $(\mathrm{P}<0.05)$. The postoperative indwelling drainage time was shorter than that in the control group $(\mathrm{P}<0.05)$. Besides, at 3, 6 and 12 months after operation, $10 \mathrm{~m}$ walking speed in the observation group was significantly higher than that in the control group $(\mathrm{P}<0.05)$. The 5 -time sit-stand time was shorter than that in the control group $(\mathrm{P}<0.05)$. At 1 week, 1 month, 3, 6 and 12 months after operation, Harris hip joint scores and visual analogue scale scores in the observation group were both superior to those in the control group $(\mathrm{P}<0.05)$. Moreover, the total hospitalization time in the observation group was shorter than that in the control group. Time of walking on crutches and walking without crutches was earlier than that in the control group $(\mathrm{P}<0.05)$. The overall proportion of postoperative chronic pain, thrombosis and failed surgery in the observation group was significantly lower than that in the control group $(\mathrm{P}<0.05)$. Finally, physical and psychological scores in the observation group after intervention were obviously higher
\end{abstract}

Correspondence to: Dr Zhifang Wang, Department of Orthopedics and Traumatology, Zhangjiagang TCM Hospital Affiliated to Nanjing University of Chinese Medicine, 4 Kangle Road, Zhangjiagang, Jiangsu 215600, P.R. China

E-mail:wzf215628@aliyun.com

Key words: artificial femoral head replacement, proximal femur locking plate, senile, femoral intertrochanteric fracture, hip joint function than those in the observation group before intervention and the control group after intervention $(\mathrm{P}<0.05)$. Artificial femoral head replacement is characterized by the short operation time, less intraoperative bleeding, fast postoperative recovery of joint function, low degree of pain and fewer complications in the treatment of senile femoral intertrochanteric fracture, which can improve the postoperative life quality of patients.

\section{Introduction}

With the progress of socialization in China, the aging of population has been increasingly prominent. The elderly population is often accompanied with various medical diseases, especially in middle-aged women who are often accompanied with osteoporosis, so the slight trauma can lead to femoral intertrochanteric fracture easily (1). Intertrochanteric fractures in senile patients are mostly unstable fractures accompanied with osteoporosis, while the fractures are often comminuted, involving the large and small intertrochanteric fractures. Mostly the femoral distance was destroyed, resulting in the loss of its mechanical support, and even involving the proximal femoral medullary cavity. At present, surgery is the preferred treatment means for the disease to avoid venous thrombosis, malnutrition, bed sores and joint stiffness, caused by long-term immobilization (2). Although there are many surgical methods for the disease, such as internal fixation with multi-Kirschner wires, with Richard nail and Gamma nail and with dynamic hip screw (DHS) locking screw (3), they will cause larger trauma, it is hard for patients, especially the senile patients, to get out of bed early after operation, and postoperative complications, such as severe pain, occur, affecting the prognosis of patients (4).

Proximal femur locking plate (PFLP) is widely used for the treatment of proximal femoral fractures in recent years, which belongs to the extramedullary fixation system (5). The PFLP is reasonably designed and anatomically matches with the proximal epiphysis of the femur. It is able to fix the coronal plane fracture of the large as well as small intertrochanteric fracture, meeting the demands of intertrochanteric comminuted fracture fixation internally.

Artificial femoral head replacement is a relative simple operation with modeled procedures, which causes less trauma, 
and patients can get out of bed early after operation thus reducing the complications caused by long-term immobilization. Besides, patients could begin early hip exercise and walk with weight to quickly restore hip function to the preoperative state. Moreover, this operation could help to avoid many complications caused by internal fixation (6). Therefore, it is recommended as one of the preferred methods in the treatment of senile femoral intertrochanteric fracture (7). In this study, the experience of performing PFLP fixation as well as artificial femoral head replacement for the senile femoral intertrochanteric fracture in recent years was summarized and its clinical application effect is reported.

\section{Patients and methods}

General data. Eighty patients with femoral intertrochanteric fractures who received artificial femoral head replacement under intraspinal anesthesia in Zhangjiagang Hospital from May 2014 to December 2016 were selected. They were aged 60-85 years, and signed the informed consent for enrollment, operation and anesthesia. At the same time, this study was discussed and approved by the Medical Ethics Committee of Zhangjiagang Hospital of Traditional Chinese Medicine Affiliated to Nanjing University of Chinese Medicine (Zhangjiagang, China). Patients complicated with severe cardiopulmonary insufficiency, severe liver and kidney function deficiency, coagulation disorders, spinal deformity, malignant tumors, fractures in other parts of lower limbs or mental illness, or who used analgesia device after operation or refused to be enrolled were excluded. Patients enrolled were divided into two groups, the observation group $(n=40)$ and the control group $(n=40)$, using the random number method. In the observation group, there were 20 males and 20 females aged $60-85$ years with an average of $73.5 \pm 1.3$ years; in terms of injured part, there were 16 cases on the left and 24 cases on the right. Based on Evans-Jensen classification (8), 2 were in type I, 6 in type II, 15 in type III, 16 in type IV and 1 in type V. In the control group, there were 21 males and 19 females aged 60-85 years with an average of $73.6 \pm 1.3$ years; in terms of injured part, there were 15 cases on the left and 25 cases on the right. Based on Evans-Jensen classification, 3 were in type I, 3 in type II, 16 in type III and 18 in type IV. The differences in sex, age and injured part and Evans-Jensen classification between the two groups were not statistically significant $(\mathrm{P}>0.05)$.

Methods. The observation group was treated with artificial femoral head replacement. The incision was entered using the Smith-Petersen method. All patients received the combined spinal-epidural anesthesia in a lateral position. A $8 \mathrm{~cm}$-long incision was made in the greater trochanter of femur till $5 \mathrm{~cm}$ below the greater trochanter of femur, followed by blunt separation to fully expose the fracture site in greater trochanter of femur. The fracture re-displacement was avoided. The femoral head and labrum acetabulare were exposed, the lateral iliac artery was ligated and then the joint capsule was cut. The femoral neck was broken from $1.5 \mathrm{~cm}$ in the femoral lesser trochanter. The femoral head was removed, and the bone marrow was enlarged. The femoral prosthesis was placed into the fracture site of femur, and bound with wire after
Table I. Comparison of relevant situations of operation between the two groups (mean \pm standard deviation).

\begin{tabular}{|c|c|c|c|}
\hline & $\begin{array}{l}\text { Operation } \\
\text { time (min) }\end{array}$ & $\begin{array}{l}\text { Intraoperative } \\
\text { bleeding }(\mathrm{ml})\end{array}$ & $\begin{array}{c}\text { Postoperative } \\
\text { drainage } \\
\text { time (days) }\end{array}$ \\
\hline Observation group & $45.6 \pm 2.8$ & $103.5 \pm 10.5$ & $2.1 \pm 0.2$ \\
\hline Control group & $63.2 \pm 3.9$ & $256.8 \pm 23.9$ & $3.3 \pm 0.3$ \\
\hline t value & 23.185 & 37.141 & 21.049 \\
\hline P-value & $<0.001$ & $<0.001$ & $<0.001$ \\
\hline
\end{tabular}

determining the location and stability. Then the prosthesis handle was removed, and the medullary cavity was filled with the bone cement. Then the prosthesis handle was placed once again at $15^{\circ}$ forward; the excess bone cement was cleaned up. The control group was treated with PFLP fixation. First, a $20 \mathrm{~cm}$-long longitudinal incision was made on the greater trochanter of femur, followed by blunt separation to expose the femoral membrane. Under the C-arm, the Kirschner wire was placed at approximately $5 \mathrm{~cm}$ under the greater trochanter. The Kirschner wire at an appropriate position under the femoral neck was used as the guide pin, and the cancellous bone screw was placed and the locking screws were screwed on.

Observational indexes. The elderly patients were all followed up for 12 months, and the relevant data were obtained through calling them or their guardians combined with outpatient follow-up. The relevant situations of operation, $10 \mathrm{~m}$ walking speed and 5-time sit-stand time at 3,6 and 12 months after operation, Harris hip score before and after operation, pain at different time-points before and after operation, total hospitalization time, time of walking on crutches and walking without crutches, complications and 36-item short-form health survey questionnaire (SF-12) scores before and after intervention were compared between the two groups.

Evaluation criteria. The length of lower limbs was measured using the tape from iliac spine to inferior margin of medial malleolus. Those with difference in length of the lower limbs greater than $1.5 \mathrm{~cm}$ were diagnosed as length discrepancy of both lower limbs; the $10 \mathrm{~m}$ walking speed was based on the measurement of $10 \mathrm{~m}$ plane linear distance using the stopwatch, and the 5-time sit-stand time was based on the measurement using the knee-high back bench and stopwatch. The pain score was measured using the visual analogue scale (VAS); the highest score (10 points) indicated severe pain, while the lowest score (0 point) indicated no pain; the higher the score was, the more severe the pain was. Harris hip function score (0-100 points): $>90$ points indicated excellent and good, while $>70$ points indicated the hip joint dysfunction. SF-12 score (0-50 points): the patient's physical function and psychological function were scored at the same time; the higher the score was, the better the life quality was.

Statistical analysis. Statistical Product and Service Solutions (SPSS) 21.0 (IBM Corp., Armonk, NY, USA) was used for the statistical analysis. All measurement data in this study 
Table II. Comparison of $10 \mathrm{~m}$ walking speed and 5-time sit-stand time at 3, 6 and 12 months after operation between the two groups (mean \pm standard deviation).

\begin{tabular}{|c|c|c|c|c|c|c|}
\hline & \multicolumn{2}{|c|}{3 months } & \multicolumn{2}{|c|}{6 months } & \multicolumn{2}{|c|}{12 months } \\
\hline & $\begin{array}{l}10 \mathrm{~m} \text { walking } \\
\text { speed }(\mathrm{m} / \mathrm{sec})\end{array}$ & $\begin{array}{l}\text { 5-time sit-stand } \\
\text { time }(\mathrm{sec})\end{array}$ & $\begin{array}{l}10 \text { m walking } \\
\text { speed }(\mathrm{m} / \mathrm{sec})\end{array}$ & $\begin{array}{l}\text { 5-time sit-stand } \\
\text { time }(\mathrm{sec})\end{array}$ & $\begin{array}{l}10 \mathrm{~m} \text { walking } \\
\text { speed }(\mathrm{m} / \mathrm{sec})\end{array}$ & $\begin{array}{c}\text { 5-time sit-stand } \\
\text { time ( } \mathrm{sec})\end{array}$ \\
\hline Observation group & $1.6 \pm 0.2$ & $56.6 \pm 11.0$ & $2.1 \pm 0.3$ & $45.2 \pm 5.7$ & $2.7 \pm 0.5$ & $40.5 \pm 5.3$ \\
\hline Control group & $0.7 \pm 0.1$ & $73.0 \pm 13.1$ & $1.6 \pm 0.2$ & $53.1 \pm 4.5$ & $2.3 \pm 0.3$ & $48.6 \pm 3.1$ \\
\hline t value & 25.456 & 6.064 & 20.126 & 7.82 & 23.32 & 5.69 \\
\hline P-value & $<0.001$ & $<0.001$ & 0.0023 & 0.0016 & 0.015 & 0.025 \\
\hline
\end{tabular}

are presented as mean \pm standard deviation, and all enumeration data are presented as percentage. $t$-test was used for the comparison of measurement data, while the Chi-square test was used for the comparison of enumeration data. One-way ANOVA test followed by post hoc test (Least Significant Difference) was performed for multiple comparisons between the groups. $\mathrm{P}<0.05$ was considered to indicate a statistically significant difference.

\section{Results}

Comparison of relevant situations of operation between the two groups. In the observation group, the operation time was significantly shorter than that in the control group, the intraoperative bleeding was less than that in the control group $(\mathrm{P}<0.05)$, and the postoperative indwelling drainage time was significantly shorter than that in the control group $(\mathrm{P}<0.05)$ (Table I).

Comparison of $10 \mathrm{~m}$ walking speed and 5-time sit-stand time at 3, 6 and 12 months after operation between the two groups. At 3 months after operation, the $10 \mathrm{~m}$ walking speed in the observation group was significantly higher than that in the control group $(\mathrm{P}<0.05)$, and the 5-time sit-stand time was shorter than that in the control group $(\mathrm{P}<0.05)$ (Table II).

Comparison of Harris hip scores before and after operation between the two groups. The Harris hip scores of the two groups before operation were $35.6 \pm 2.1$ and $35.5 \pm 2.1$ points, and there was no statistically significant difference $(\mathrm{t}=0.000$; $\mathrm{P}>0.05)$. At 1 week, 1 month, 3, 6 and 12 months after operation, the Harris hip scores of the observation group were $49.6 \pm 3.1,68.9 \pm 6.5,85.6 \pm 7.2,90.7 \pm 5.3$ and $93.1 \pm 2.3$ points, respectively, which were superior to those of the control group in the same period $(40.3 \pm 2.6,56.1 \pm 4.0,70.3 \pm 5.0,86.8 \pm 3.5$ and $88.9 \pm 2.6$ points $)(\mathrm{t}=14.537,10.607,11.039,9.835,12.117$; $\mathrm{P}<0.05$ ) (Fig. 1).

Comparison of VAS pain scores at different time-points before and after operation. The VAS pain scores of the two groups before operation were $7.5 \pm 0.3$ and $7.5 \pm 0.4$ points, and there was no statistically significant difference $(\mathrm{t}=0.213 ; \mathrm{P}>0.05)$. At 1 week, 1 month, 3, 6 and 12 months after operation, the VAS pain scores of the observation group were $6.1 \pm 0.2$, $2.5 \pm 0.2,1.3 \pm 0.1,0.8 \pm 0.4$ and $0.5 \pm 0.2$ points, respectively, which were superior to those of the control group in the same

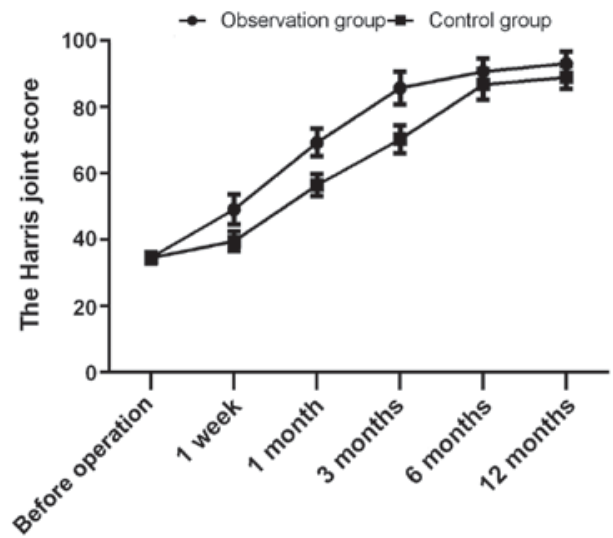

Figure 1. Comparison of Harris hip score before and after operation between the two groups: there is no statistically significant difference in the Harris hip joint score between the two groups before operation $(\mathrm{P}>0.05)$; at 1 week, 1 month and 3 months after operation, the Harris hip joint scores in the observation group are superior to those in the control group in the same period $(\mathrm{P}<0.05)$.

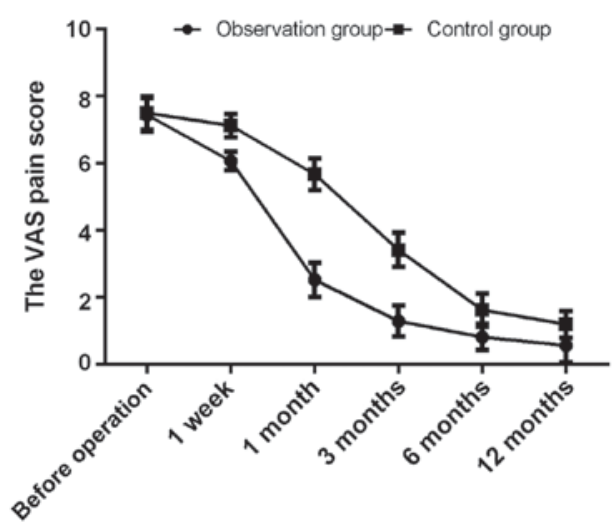

Figure 2. Comparison of VAS pain scores at different time-points before and after operation: there is no statistically significant difference in the VAS pain score between the two groups before operation $(\mathrm{P}>0.05)$; at 1 week, 1 month and 3 months after operation, the VAS pain scores in the observation group are superior to those in the control group in the same period $(\mathrm{P}<0.05)$.

period $(7.0 \pm 0.2,5.6 \pm 0.3,3.5 \pm 0.2,1.6 \pm 0.3$ and $1.2 \pm 0.2$ points $)$ $(\mathrm{t}=20.125,54.378,44.000,32.236,25.560 ; \mathrm{P}<0.05)($ Fig. 2).

Comparison of total hospitalization time and time of walking on crutches and walking without crutches between the two groups. The total hospitalization time in the observation group was 
Table III. Comparison of total hospitalization time and time of walking on crutches and walking without crutches between the two groups (days, mean \pm standard deviation).

\begin{tabular}{lccc}
\hline & $\begin{array}{c}\text { Total } \\
\text { hospitalization } \\
\text { time }\end{array}$ & $\begin{array}{c}\text { Time of } \\
\text { walking } \\
\text { on crutches }\end{array}$ & $\begin{array}{c}\text { Time of } \\
\text { walking } \\
\text { without crutches }\end{array}$ \\
\hline $\begin{array}{l}\text { Observation } \\
\text { group }\end{array}$ & $14.6 \pm 0.8$ & $10.2 \pm 0.3$ & $96.3 \pm 8.5$ \\
$\begin{array}{l}\text { Control } \\
\text { group }\end{array}$ & $16.5 \pm 1.1$ & $15.6 \pm 0.9$ & $158.6 \pm 11.4$ \\
t value & 14.572 & 36.000 & 27.709 \\
$\begin{array}{l}\text { P-value } \\
<0.001\end{array}$ & $<0.001$ & $<0.001$ \\
\hline
\end{tabular}

Table IV. Comparison of complications between the two groups $(\mathrm{n}, \%)$.

\begin{tabular}{lccc}
\hline & $\begin{array}{c}\text { Postoperative } \\
\text { chronic pain }\end{array}$ & $\begin{array}{c}\text { Failure of } \\
\text { operation }\end{array}$ & $\begin{array}{c}\text { Total incidence } \\
\text { rate }\end{array}$ \\
\hline Observation group & 1 & 2 & $3(7.5 \%)$ \\
Control group & 3 & 8 & $11(27.5 \%)$ \\
$\chi^{2}$ & & & 4.242 \\
P-value & & & 0.039 \\
\hline
\end{tabular}

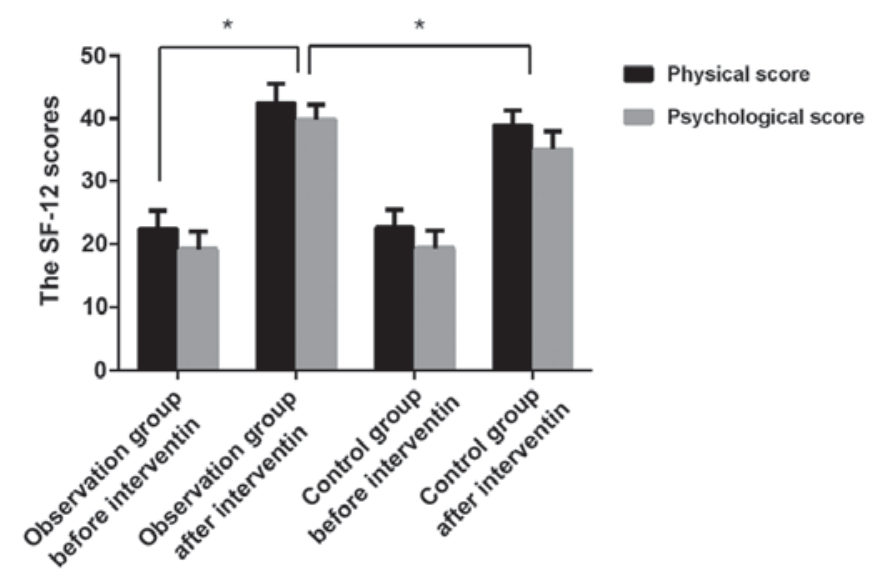

Figure 3. Comparison of SF-12 scores between the two groups before and after intervention: there were no statistically significant differences in the SF-12 scores between the two groups before intervention $(\mathrm{P}>0.05)$; the physical score and psychological score in the observation group after intervention were obviously higher than those in the observation group before intervention and the control group after intervention $\left({ }^{*} \mathrm{P}<0.05\right)$.

shorter than that in the control group, and the time of walking on crutches and walking without crutches was earlier than that in the control group $(\mathrm{P}<0.05)$ (Table III).

Comparison of complications between the two groups. The proportions of postoperative chronic pain, failed operation (including prosthesis or internal fixation loose and nonunion) in the observation group were significantly lower than those in the control group $(\mathrm{P}<0.05)$ (Table IV).
Comparison of SF-12 scores between the two groups before and after intervention. In SF-12 scores, the physical score and psychological score in the two groups before intervention were $23.1 \pm 1.7,18.9 \pm 1.5$ and $23.2 \pm 1.7,18.8 \pm 1.5$ points, respectively, and there were no statistically significant differences $(\mathrm{t}=0.263$ and 0.298; $\mathrm{P}>0.05)$. After intervention, the physical score and psychological score in the observation group were $43.5 \pm 2.3$ and $40.8 \pm 2.0$ points, respectively, which were obviously higher than those in the observation group before intervention $(\mathrm{t}=45.111$ and 55.403; $\mathrm{P}<0.05)$ and the control group after intervention $(38.6 \pm 2.1$ and $35.6 \pm 1.9$ points) $(\mathrm{t}=9.950$ and 11.923; P<0.05) (Fig. 3).

Comparison of X-ray between the two groups before and after intervention. Preoperative and postoperative X-ray comparison of two groups of patients are shown in Fig. 4 (A and B represent the preoperative and postoperative X-ray of the observation group; $\mathrm{C}$ and D represent the preoperative and postoperative X-ray of the control group).

\section{Discussion}

Femoral intertrochanteric fracture is a kind of common fracture in skeletal system in the elderly, which is mainly based on osteoporosis. The pathological fracture will be caused under the action of external forces, or even slight forces. If there is no timely and effective treatment, the mortality rate will be significantly increased (9). The key in the successful treatment of this disease is the choice of surgical method and surgical techniques (10). The surgical treatment of senile femoral intertrochanteric fracture mainly aims to promote the recovery of autonomic activities of patients to throw away the crutches as soon as possible (11) and reduce the complications caused by long-term immobilization (12). Therefore, the treatment of this disease should be targeted: i) strong internal fixation; ii) early and safe activities; iii) less surgical trauma and short operative time; iv) better functional recovery after surgery, so the surgical treatment within $48 \mathrm{~h}$ is recommended if medical conditions permit.

Proximal femoral locking plate is designed based on the anatomy of the proximal femur (5). Due to the locking function of its screw thread in distance and depth as well as the locking function of screw tail, the screw could lock the plate hole to fix the fracture. At the same time, the plate and screw can be fixed through the thread, making the locking plate a whole part, so that the fracture could be fixed on the 'surface', which could avoid stress concentration and enhance the capacity of anti-rotation and internal fixation. It is applied to the senile intertrochanteric fracture combined with osteoporosis (13). The PFLP surgery does not require shaping to make the large intertrochanteric fractures and the small intertrochanteric fractures to be well fixed. The upper end of the plate consists of 3 cancellous bone locking screws, which can effectively prevent the occurrence of hip varus and maintain the stability of the broken end. The PFLP is easy to operate and has a good short-term efficacy, allowing early activity. The 40 cases of the control group in our study had good effect overall, while the follow-up Harris hip function score, VAS score and SF-12 were improved compared with those of preoperative conditions. However, there were 8 cases $(20 \%)$ of internal fixation 

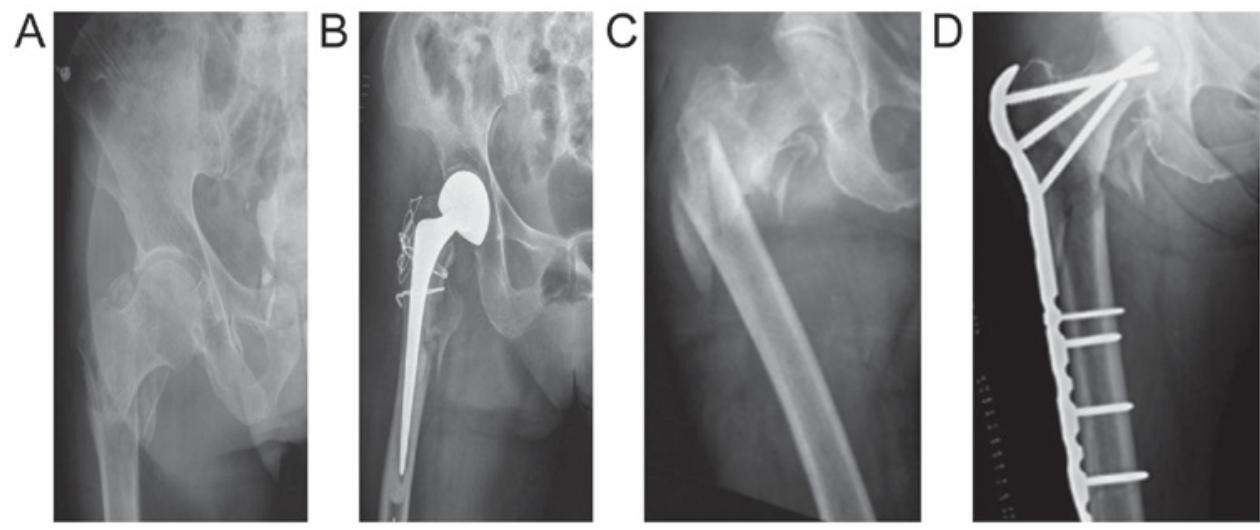

Figure 4. Comparisons of X-ray between the two groups before and after intervention. Preoperative and postoperative X-ray comparison of two groups of patients are shown. (A and B) The preoperative and postoperative X-ray of the observation group; (C and D) The preoperative and postoperative X-ray of the control group.

loosening and nonunion in the treatment of PFLP, which might be related to the blood supply and the seriousness of osteoporosis in elderly patients.

Jin et al have shown that the failure rate of internal fixation of $8-16 \%$ in the unstable intertrochanteric fracture (14). Therefore, it is suggested by some researchers that treatment of artificial joint replacement should be adopted for femoral intertrochanteric fractures in special populations (15). This method allows immediate and effective recovery of the function of the hip joint while the patients could resume the weight-bearing function as soon as possible, making them leave the bed early and shortening the bed rest time. The patients get good recovery of their limb function and quality of life is improved as well. Furthermore, the artificial joint replacement could avoid hip varus deformity, failure of internal fixation and complications caused by long-term immobilization (16). Babst et al demonstrated that we should not simply rely on some strong internal fixtures, but also should pay attention to the reset. The ideal reset could stabilize the fracture, however, on this basis the internal fixation will increase its own strength (17). Compared with the artificial femoral head replacement, the proximal femoral locking plate fixation would cause larger surgical trauma, more surgical field exposure and more surgical bleeding to achieve a better reset, which exerts greater impact on the organ function of patients. In contrast, the observation group in our study experienced short surgery time, less bleeding and fast postoperative recovery. Moreover, the total hospitalization time of the observation group was shorter than that of the control group; the walking time with the crutches and the time taken for walking without crutches were both earlier in the observational group than in the control group, which were conducive for early functional activities in patients and reduced complications caused by long-term immobilization.

Postoperative follow-up showed that the Harris hip score of the observation group was better than the control group, while the pain VAS score was lower than the control group. In addition, the comparisons of SF-12 scores between the two groups before and after intervention revealed that in SF-12 scores, the physical score and psychological score in the observation group after intervention were obviously superior to those in the observation group before intervention and the control group after intervention, which further indicated that artificial femoral head replacement in the treatment of senile femoral intertrochanteric fracture has a positive significance in improving the overall life quality of patients after operation. Moreover, the stable artificial femoral head replacement can make patients get out of bed and bear load earlier after operation (18). At the same time, it avoids the pain caused by secondary internal fixation, and improves patients' confidence and compliance (19). It is particularly suitable for the senile (18) and unstable fractures $(20,21)$, and those with obvious osteoporosis and old fractures receiving failed conventional internal fixation (22).

In conclusion, artificial femoral head replacement is characterized by the short operation time, less intraoperative bleeding, fast postoperative recovery of joint function, low degree of pain and fewer complications caused by long-term immobilization, which can improve the postoperative life quality of patients. It has a good clinical efficacy in the treatment of senile femoral intertrochanteric fractures. At the same time, the orthopedic surgeon should take full account of the patient's age, type of fracture, bone quality, with or without other medical diseases and economic conditions in the face of elderly patients with intertrochanteric fractures, select the appropriate treatment to minimize patients pain and to achieve rapid recovery.

\section{Acknowledgements}

Not applicable.

\section{Funding}

No funding was received.

\section{Availability of data and materials}

All data generated or analyzed during this study are included in this published article.

\section{Authors' contributions}

HS designed the study. LX and ZW were responsible for data collection and analysis. ZW performed the operations. HS 
prepared the manuscript. All authors read and approved the final manuscript.

\section{Ethics approval and consent to participate}

This study was approved by the Ethics Committee of Zhangjiagang Hospital of Traditional Chinese Medicine Affiliated to Nanjing University of Chinese Medicine (Zhangjiagang, China). Signed informed consents were obtained from the patients or guardians.

\section{Consent for publication}

Not applicable.

\section{Competing interests}

The authors declare that they have no competing interests.

\section{References}

1. Peng MJ, Chen HY, Hu Y, Ju X and Bai B: Finite element analysis of porously punched prosthetic short stem virtually designed for simulative uncemented hip arthroplasty. BMC Musculoskelet Disord 18: 295, 2017.

2. Khanna R, Kokubo T, Matsushita T and Takadama H: Fabrication of dense $\alpha$-alumina layer on Ti-6Al-4V alloy hybrid for bearing surfaces of artificial hip joint. Mater Sci Eng C 69: 1229-1239, 2016.

3. Zhang BL, Wang F, Tian MB, Yin WL, You XY, Li D, Ma LG and Xing LQ: Articular capsule repair in initial artificial hip replacement via anterolateral approach to the hip joint. J Biol Regul Homeost Agents 30: 441-447, 2016.

4. Lin YT, Wu JS and Chen JH: The study of wear behaviors on abducted hip joint prostheses by an alternate finite element approach. Comput Methods Programs Biomed 131: 143-155, 2016.

5. Fankhauser F, Boldin C, Schippinger G, Haunschmid C and Szyszkowitz R: A new locking plate for unstable fractures of the proximal humerus. Clin Orthop Relat Res 430: 176-181, 2005.

6. Hsu CJ, Chou WY, Chiou CP, Chang WN and Wong CY: Hemiarthroplasty with supplemental fixation of greater trochanter to treat failed hip screws of femoral intertrochanteric fracture. Arch Orthop Trauma Surg 128: 841-845, 2008.

7. Li N, Liu HN, Gong XF, Zhu SW, Wu XB and He L: Epidemiological analysis of hospitalized patients with femoral neck fracture in a first-class hospital of Beijing. Beijing Da Xue Xue Bao Yi Xue Ban 48: 292-296, 2016 (In Chinese).

8. Jensen JS and Michaelsen M: Trochanteric femoral fractures treated with McLaughlin osteosynthesis. Acta Orthop Scand 46: 795-803, 1975

9. Richmond J, Aharonoff GB, Zuckerman JD and Koval KJ: Mortality risk after hip fracture. J Orthop Tauma 17: 2-5, 2003.
10. van Embden D, Rhemrev SJ, Meylaerts SA and Roukema GR: The comparison of two classifications for trochanteric femur fractures: the AO/ASIF classification and the Jensen classification. Injury 41: 377-381, 2010.

11. Khanna R, Kokubo T, Matsushita T, Nomura Y, Nose N, Oomori Y, Yoshida T, Wakita K and Takadama H: Novel artificial hip joint: A layer of alumina on Ti-6Al-4V alloy formed by micro-arc oxidation. Mater Sci Eng C 55: 393-400, 2015.

12. Clarke A, Pulikottil-Jacob R, Grove A, Freeman K, Mistry H, Tsertsvadze A, Connock M, Court R, Kandala NB, Costa M, et al: Total hip replacement and surface replacement for the treatment of pain and disability resulting from end-stage arthritis of the hip (review of technology appraisal guidance 2 and 44): Systematic review and economic evaluation. Health Technol Assess 19: $1-668,2015$.

13. Konstantinidis L, Papaioannou C, Mehlhorn A, Hirschmüller A, Südkamp NP and Helwig P: Salvage procedures for trochanteric femoral fractures after internal fixation failure: biomechanical comparison of a plate fixator and the dynamic condylar screw. Proc lnst Mech Eng H 225: 710-717, 2011.

14. Jin WJ, Dai LY, Cui YM, Zhou Q, Jiang LS and Lu H: Reliability of classification systems for intertrochanteric fractures of the proximal femur in experienced orthopaedic surgeons. Injury 36 : 858-861, 2005.

15. Hwang DS, Kwak SK and Woo SM: Results of cementless hemiarthroplasty for elderly patients with unstable intertrochanteric fractrres. J Korean Hip Soc 16: 386-391, 2004.

16. Chan KC and Gill GS: Cemented hemiarthroplasties for elderly patients with intertrochanteric fractures. Clin Orthop Relat Res 371: 206-215, 2000.

17. Babst R, Renner N, Biedermann M, Rosso R, Heberer M, Harder F and Regazzoni P: Clinical results using the trochanter stabilizing plate (TSP): the modular extension of the dynamic hip screw (DHS) for internal fixation of selected unstable intertrochanteric fractures. J Orthop Trauma 12: 392-399, 1998.

18. Feng W, Hao T, Liu WL, Jia YF, Hao ZT and Bai SB: Clinical outcome of endoprosthetic replacement for failed treatment of intertrochanteric fractures: A retrospective case series. Pak J Med Sci 29: 633-637, 2013.

19. Lizhang J, Taylor SD, Jin Z, Fisher J and Williams S: Effect of clearance on cartilage tribology in hip hemi-arthroplasty. Proc Inst Mech Eng H 227: 1284-1291, 2013.

20. Suzuki A, Koshida K and Matsubara K: Adjustment of overestimated CT-based attenuation correction on bone SPECT/CT after hip-resurfacing arthroplasty. J Nucl Med Technol 41: 203-207, 2013.

21. Figved W, Dahl J, Snorrason F, Frihagen F, Röhrl S, Madsen JE and Nordsletten L: Radiostereometric analysis of hemiarthroplasties of the hip - a highly precise method for measurements of cartilage wear. Osteoarthritis Cartilage 20: 36-42, 2012

22. Yu X, Jiang W, Pan Q, Wu T, Zhang Y, Zhou Z and Du D: Umbrella-shaped, memory alloy femoral head support device for treatment of avascular osteonecrosis of the femoral head. Int Orthop 37: 1225-1232, 2013.

This work is licensed under a Creative Commons Attribution-NonCommercial-NoDerivatives 4.0 International (CC BY-NC-ND 4.0) License. 